\title{
Implementing BIM for industrial and heritage building conversion
}

\author{
Miroslavas Pavlovskis*, Darius Migilinskas, Jurgita Antuchevičienė, Vladislavas Kutut \\ Department of Construction Management and Real Estate, Faculty of Civil Engineering, \\ Vilnius Gediminas Technical University, Vilnius, Lithuania
}

\begin{abstract}
From systemic perspective reconstruction and restoration of industrial buildings are similar to historical and cultural heritage buildings. The maintenance and reuse of these buildings becoming more and more important research area worldwide. This importance must increase the information management demand but however, the most advanced digital technologies are rarely used. Use of 3D modelling technologies or whole building information modelling (BIM) methodology can help to save digital information of historic buildings is a significant effort to preserve the heritage and retain its most valuable features.
\end{abstract}

Keywords: heritage building, industrial buildings, BIM, "As-Built” 3D model.

\section{Introduction}

Reconstruction of existing buildings, including restoration and reconstruction of industrial buildings and historic buildings, is an area where modern digital technologies are still less applied. Building information modeling (BIM) technology is usually applied to new buildings. Due to specific nature of tasks to be solved and the lack of spatial data, there are not many examples of BIM applications to existing buildings, but this is a rapidly expanding area in the context of research and professional practice. However, 3D documentation of historic buildings is a necessity for preservation and proper management of build heritage (Volk, Stengel, \& Schultmann, 2014; Anton, Medjdoub, Shrahily, \& Moyano, 2018).

The use of technologies in historical, cultural heritage and industrial heritage reconstruction projects is similar as it differs only at the level of available information and potential intervention.

The analysis of reconstruction projects shows that it is necessary to monitor design, construction and maintenance stages. The new design methods not only significantly simplify building design, construction and operation, but also make all processes more efficient using BIM. Although the processes are similar to ones that are carried out in new construction projects, however, there are some differences, and the main one is primary data collection, which is not always qualitative and is limited due to the lack of information (Pavlovskis, Migilinskas, Antuchevičienė, Urba, \& Zigmund, 2017).

The main advantage of digital measurements is the ability of accurate measuring hard-to-reach and sometimes invisible places, to detail large-scale or complex surfaces and objects with many details. This helps to solve complex cases where architectural manual measurements are not feasible, difficult to implement, or financially unreasonable.

The same information technology, advanced computer and data processing software, high-precision laser scanning equipment, high definition and photogrammetric recording equipment, reliable positioning and precise aerial photography equipment (planes and drones) were used. Using digital data can accurately determine the extent of defects and planned works, thus not only identifying and solving problems of heritage object, but also saving the customer's funds.

The aim of the presented research is implementing BIM technologies for industrial and heritage building conversion. Research methods and results - creation of BIM "As-Built" 3D-models of industrial and heritage buildings with the use of various software and tools, analysis of the necessary data and the complexities encountered in the process.

\footnotetext{
${ }^{*}$ Corresponding author. E-mail: miroslavas.pavlovskis@vgtu.lt
}

(C) 2019 Authors. Published by VGTU Press. This is an open-access article distributed under the terms of the Creative Commons Attribution (http://creativecommons.org/licenses/by/4.0/) License, which permits unrestricted use, distribution, and reproduction in any medium, provided the original author and source are credited. 


\section{Case study \& Results}

In order to research a building, be it an elementary house or a huge castle, one must first get to know it.

The authors implemented two experimental projects. The first one - old equipment repair factory, located in Vilnius, Lithuania. Information models for both initial and refurbished building are prepared. Parameter object correlation with laser scanning data enabled creation of a virtual 3D model of the historic building. This detailed 3D model contains most of the information about the object and the elements of the object, such as used building materials, operating cost reduction schedules, energy consumption, visualization, drawings, cuts, etc. (Figure 1).

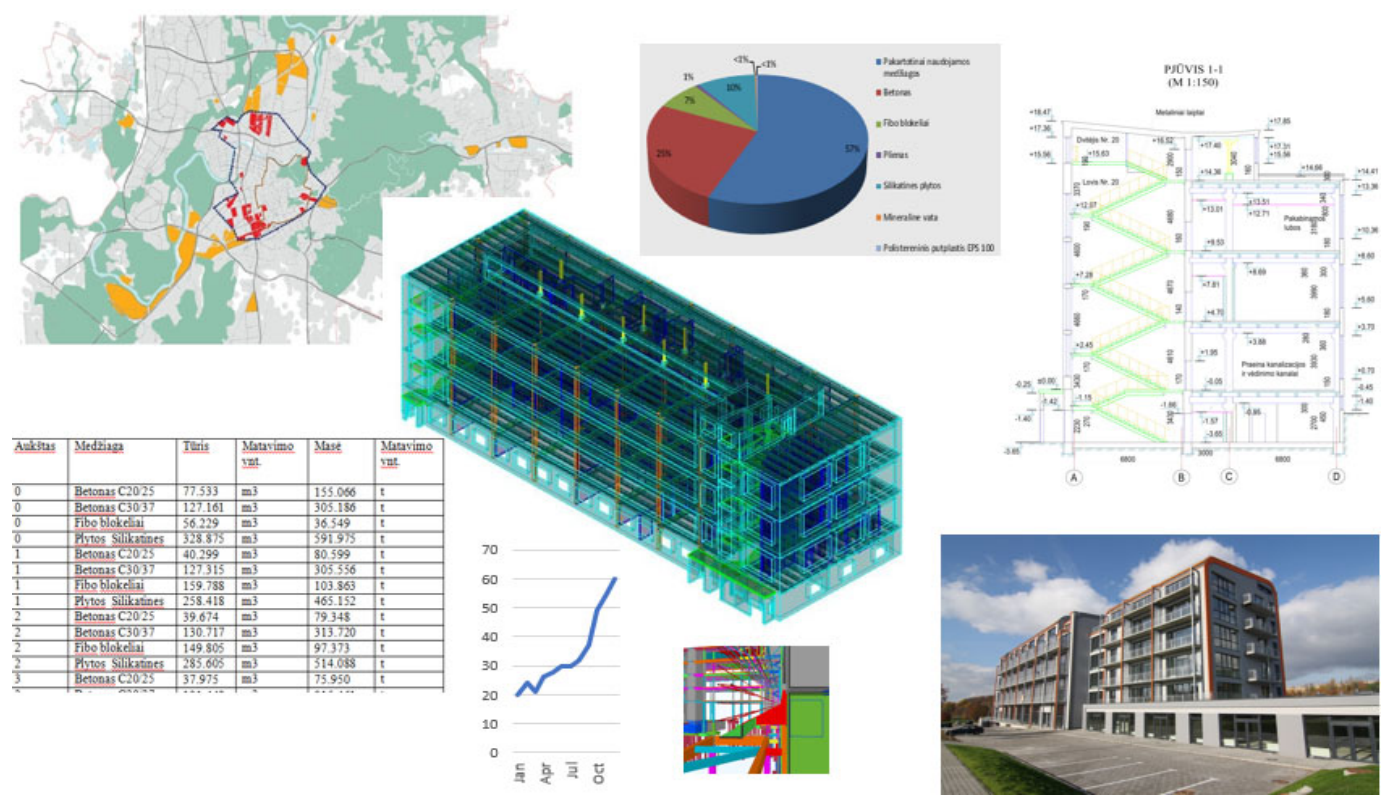

Figure 1. Detailed factory 3D model with information about the object

The next example of digital technology application, we would like to present "As-Built" 3D model creation of Sapieha Palace built in Baroque style in 1689-1691 in Vilnius, Lithuania. Research methods and tools - initial data collection by historical drawing analysis, manual measurement and photogrammetry methods. For initial data preparation were used the DJI Mavic Pro drone with a DJI FC220 digital camera with 3-axis stabilization system and a navigation system for positioning. For photo processing, Agisoft PhotoScan software was applied. After this, a cloud of points was combined with a sketch in the Revit software (Figure 2), and on the basis of this a 3D model was created.

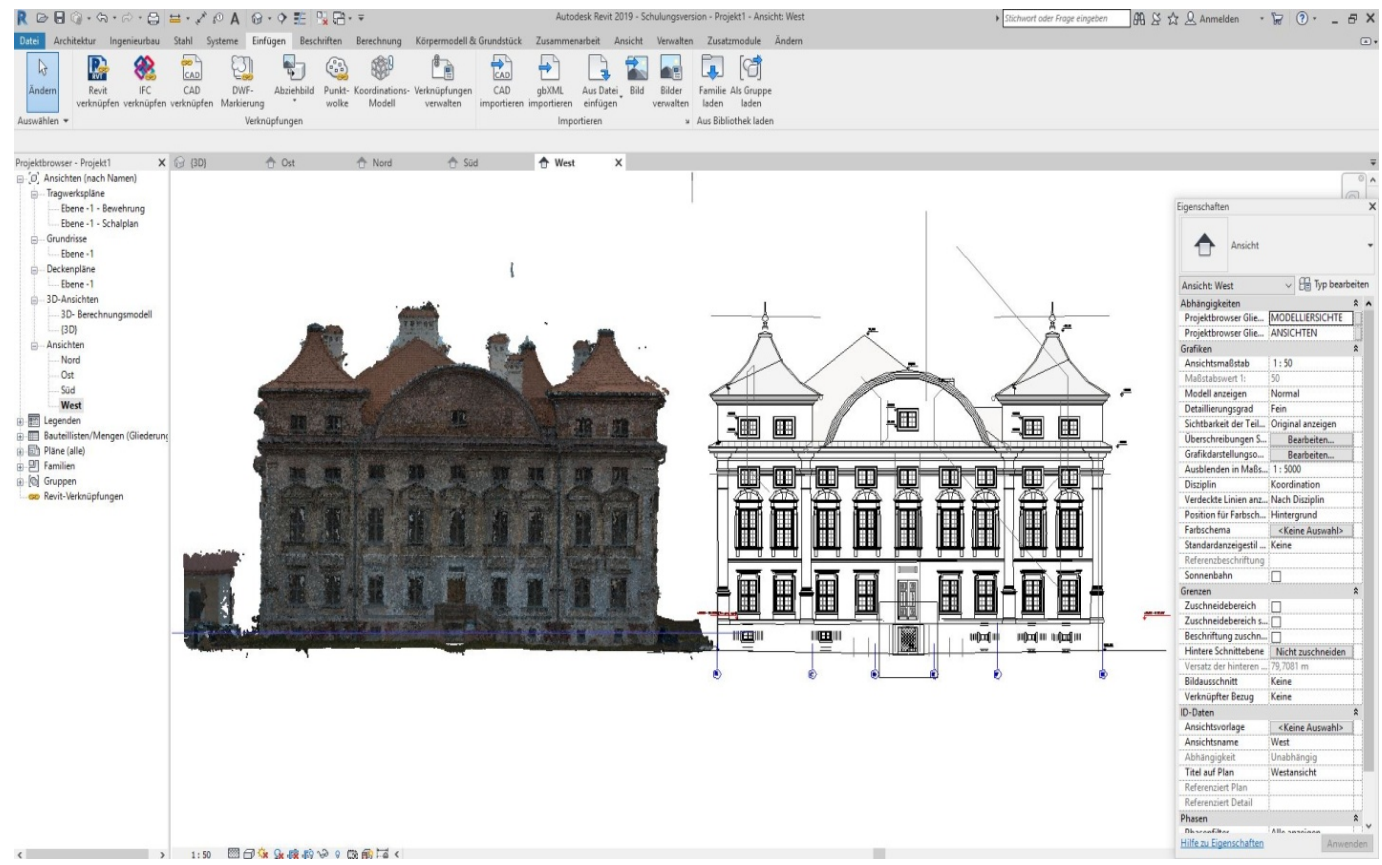

Figure 2. Drawings and point cloud combination 
Data collection from drawings begins with the examination of archival documents. Design of the building, drawings, section planes, materials used, documentation related to the repair works of the building or re-planning of the premises are analyzed. This posed a serious problem, as it is difficult to find historical descriptive and graphical information and design solutions. Often historical drawings do not correspond to reality, because the owners have reorganized the premises, annexed the building or demolished part of the building, they made an opening for a new window or foreclosure. The reasons mentioned and the inaccuracies or errors in the drawings prolong the time of collection of data and require additional checks or measurements on the site (Figure 3).

Manual measuring and drawing are tasks for specialists who are specially trained and have experience with historical forms and structures of buildings. To record correctly the complex state of a structure, there must be not only exactitude of measurement, but also above all exactitude of representation. There is a basic rule for achieving this goal: measuring and drawing must always take place on site in a combined process. Hand measurement of distances using the measuring tape has a very old tradition, but it demands special care and repeated checking (Schuller, 2002).

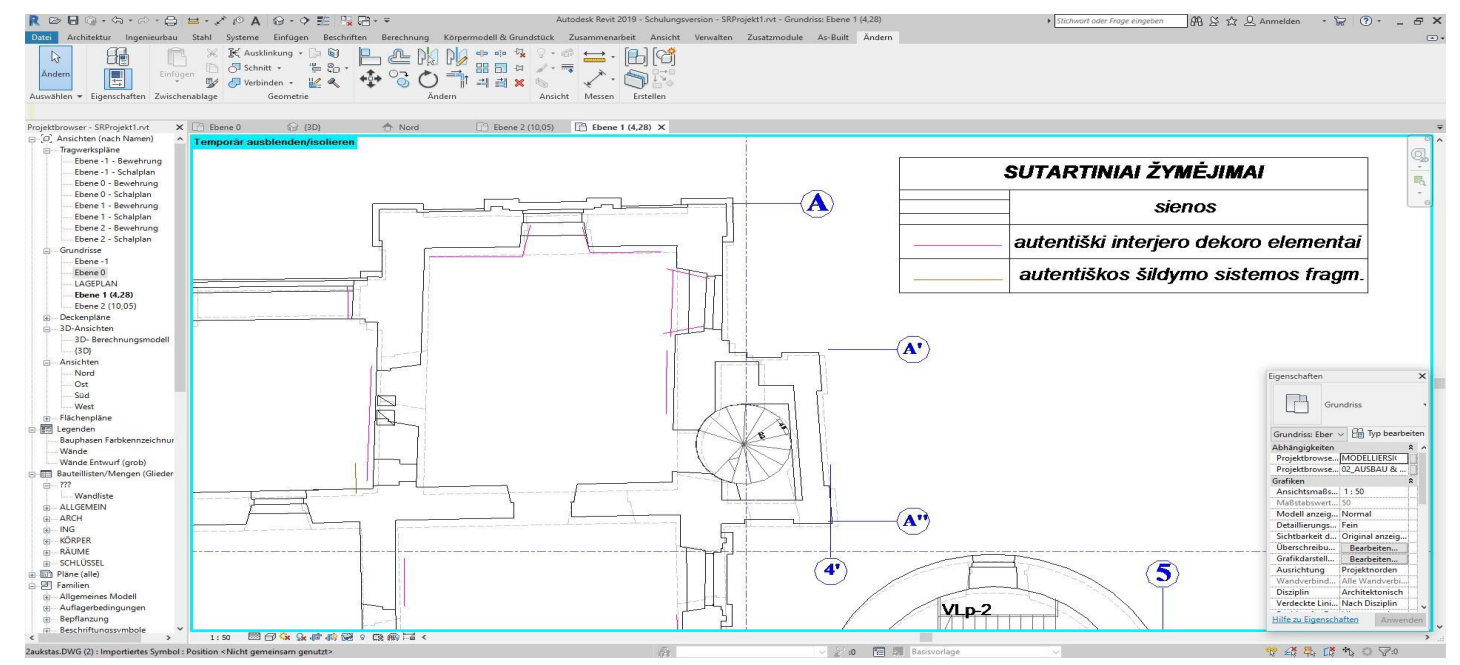

Figure 3. Mismatched graphical information from old drawings with current measuring

Other complexity originated during data processing tasks. It is especially difficult to compile and process gigabytes of data that determine computing points cloud processing time. On Figure 4 one can see that creating a model from photos lasted for more than 2 days.

Historical buildings are irregular and characterized by heterogeneous and complex shapes. In addition, the action of time causes damages and deformations on the architectural elements. Mesh surfaces can represent complex objects that cannot be described by simple geometric rules (Bruno \& Roncella, 2018).

Such inaccuracies and threats are detected regardless of which type of heritage building is selected for research or which software is used. This indicates the importance of the problem and the course of future research.

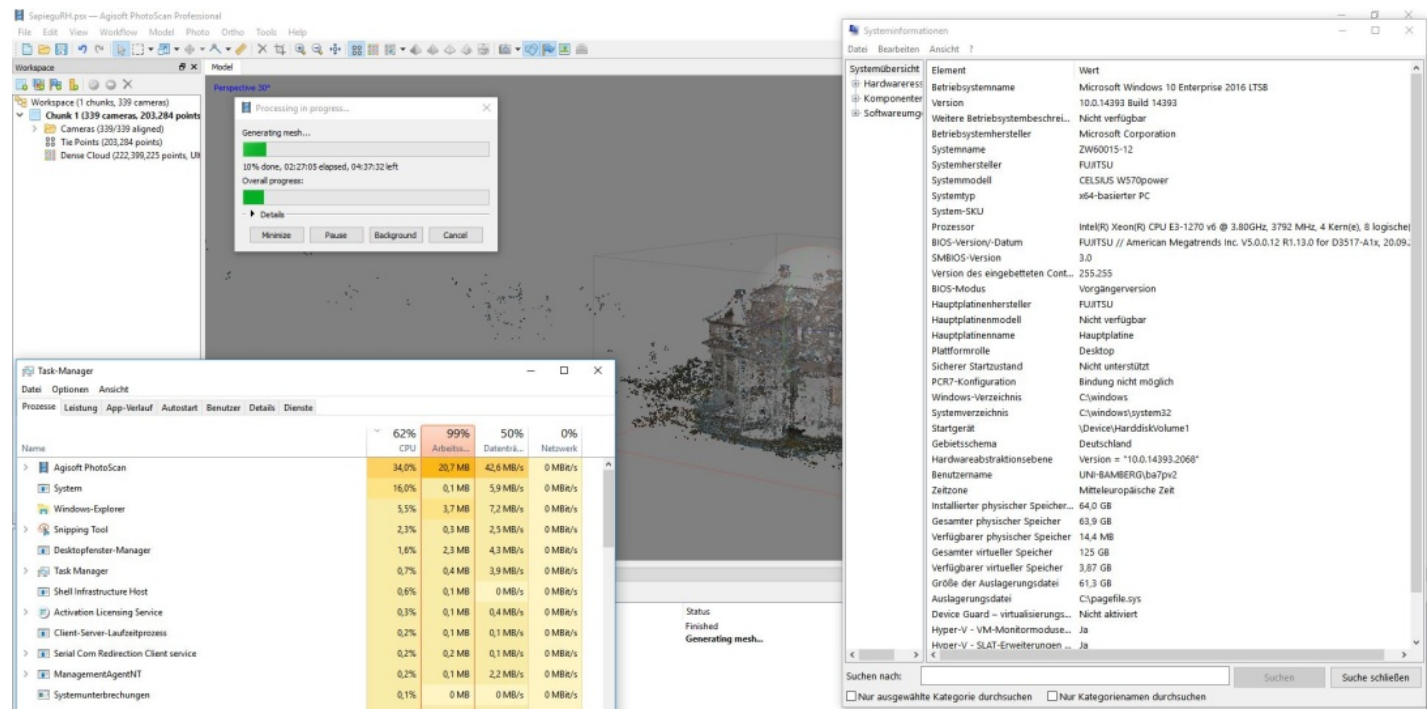

Figure 4. CPU and memory usage during model generating 


\section{Discussions \& conclusions}

Benefits of building information modeling are difficult to measure because different participants of a construction project expect different results from the BIM implementation in industrial and heritage buildings. Some of benefits of BIM uses, such as preliminary/detailed visualization, review of structural solutions and alike can be used by all project participants. However, there are other special benefits of BIM uses, which are specific to stakeholders, for example, analysis of engineering system parameters.

It is not enough to have the most advanced and accurate equipment - expertise, skills and qualifications are necessary. It is especially difficult to compile and process gigabytes of data that determine computing points cloud processing time. Finally, we must keep in mind that a BIM model library must contain building element sets that are associated with carefully identified building cultural values and valuable properties, and other valuable information that needs to be preserved for a future.

This research provides the basis for further construction heritage (industrial buildings, historical and cultural heritage buildings) research.

\section{References}

Anton, D., Medjdoub, B., Shrahily, R., \& Moyano, J. (2018). Accuracy evaluation of the semi-automatic 3D modeling for historical building information models. International Journal of Architectural Heritage, 12(5), 790-805. https://doi.org/10.1080/15583058.2017.1415391

Bruno, N., \& Roncella, R. (2018). A restoration oriented HBIM system for cultural heritage documentation: The case study of parma cathedral. International Archives of the Photogrammetry, Remote Sensing \& Spatial Information Sciences, 42(2), 171-178. https://doi.org/10.5194/isprs-archives-XLII-2-171-2018

Pavlovskis, M., Migilinskas, D., Antuchevičienè, J., Urba, I., \& Zigmund, V. (2017). Problems in reconstruction projects, BIM uses and decision-making: Lithuanian case studies. Procedia Engineering, 208, 125-128. https://doi.org/10.1016/j.proeng.2017.11.029

Schuller, M. (2002). Building archaeology. Monuments and Sites VII. München.

Volk, R., Stengel, J., \& Schultmann, F. (2014). Building Information Modeling (BIM) for existing buildings - Literature review and future needs. Automation in Construction, 38, 109-127. https://doi.org/10.1016/j.autcon.2013.10.023 